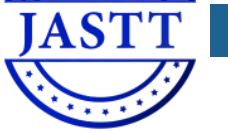

\title{
Spatiotemporal Analysis of Vegetation Cover in Kurdistan Region-Iraq using MODIS Image Data
}

\author{
Yaseen T. Mustafa \\ Dept. of Environmental Science, Faculty of Science, University of Zakho, Kurdistan Region-Iraq (yaseen.mustafa@uoz.edu.krd)
}

\begin{abstract}
The rapidly and wide use of remote sensing and accurately obtain information on the spatiotemporal distribution of large-scale vegetation is of great significance for improving and managing the Environment. To assess and analyze the spatiotemporal variation of vegetation status in Kurdistan Region of Iraq (KRGI), we used time series NDVI-based vegetation that are extracted from MOD13Q1 MODIS product over 20 years $(2000$ - 2019). The results showed that vegetation was mainly distributed in the north-east to south-east of the KRGI, while west region has less distributed and almost no vegetation. This is clearly remarkable in the south-west part of the region (Garmian administration). While, the most dominated vegetation province was Duhok province in KRGI during study period. There is a noticeable temporal variation in vegetation over a period of 20 -year in the KRGI. The lower vegetated cover area is observed in the years 2000,2008 , and 2009. The increase/decrease of vegetated cover area is not only effected by climate conditions. The anthropogenic resource is also one of the main resources that has a major influence on the increase/decrease of vegetation.
\end{abstract}

Keywords: NDVI, MODIS Images, Vegetation, KRGI.

Received: January 5 / Accepted: February 20 / Online: March 10

\section{INTRODUCTION}

Vegetation cover has a critical role in climate change by sequestering, or storing, large quantities of carbon. Several climate research projects focused on the quantification of vegetation cover to study the drought severity [1-3]. Moreover, it has been used to investigate a relationship with soil [4], temperature and urban form [5-8].

Vegetation mapping presents valuable information for understanding the natural and man-made environments through quantifying vegetation cover. Longtime monitoring measurements of spatial vegetation variation can generate a useful information regarding land surface cover changes and its trends. Satellite data can provide a long-term and continues information on spatial and temporal variation of vegetation. Measures of remotely sensed vegetation cover and density include foliage cover [9], woody and non-woody cover [10], and absorbed photosynthetically active radiation[11].

Several researchers were utilized satellite images to reveal the status of the vegetation coverage (forest, grass, crops, ... etc.) [12-17]. One of the satellite that provide continues data (spatially and temporally) is Moderate Resolution Imaging Spectroradiometer (MODIS). It also provides a new data source that includes atmosphere, land and ocean for integrated studies of scientific mechanism of the evolution of the Earth's environment and its changes. Mustafa [18] estimated Leaf Area Index (LAI) in heterogeneous forests using MODIS data. He provided approach for estimating the variation of LAI over time. Gholamnia, et al. [19] analysed spatiotemporal behaviour of vegetation cover in the Kurdistan province of Iran using Normalized Difference Vegetation Index (NDVI) time series derived MODIS observation. Moreover, an attempt on the application of remote sensing data was achieved for extraction of phonological variables for alluvial plain Kamrup Sal forest of northeast India [20]. They used time series NDVI datasets of MODIS product for a period of 10 years. Some investigations on the application of remote sensing data for vegetation analysing were conducted at parts of the Kurdistan region of Iraq (KRGI). For example, Hussein, et al. [21] assessed the spatiotemporal variations of vegetation index in Erbil and its environment between 2000 and 2015, using MODIS satellite data. Till date, no attempt has been made to analyse spatiotemporal variation of vegetation cover in the whole KRGI using remote sensing data. For this reason, the current study is an attempt on the application of remote sensing data for estimating and analysing of vegetation coverage for KRGI over a period of 20 years (2000-2019). 


\section{STUDY AREA}

Kurdistan Region of Iraq (KRGI) is a federal region that is located in the northeast of Iraq. It is bordered by Turkey from the north, Iran from the east, Syria from the north-west and from the south and southwest is Iraqi part. KRGI located between latitudes $33^{\circ} 57^{\prime} 58.5^{\prime \prime} \quad-37^{\circ} 20^{\prime} 33.55^{\prime \prime} \mathrm{N}$ and longitudes $42^{\circ} 20^{\prime} 25.36^{\prime \prime}-46^{\circ} 19^{\prime} 16.475 \mathrm{E}$ (Fig. 1), and cover an area around $50325.82 \mathrm{~km}^{2}$ with elevation ranges $(88 \mathrm{~m}-3600 \mathrm{~m})$. It has three provinces (Duhok, Erbil, Sulaymaniyah), and Garmian administration, where the city of Erbil is the capital. The KRGI is characterized by a Mediterranean climate, which is cold and rainy in winter and hot and dry in summer [22]. KRGI can be divided into the Zagros Mountains and the Foothills. The climate of Kurdistan is governed by high precipitation rates in the northern parts and drier climate in the plains [23]. The precipitation starts from October to May with the amount of 350 in the southwestern parts to more than 1,200 $\mathrm{mm}$ in northern and north-eastern parts. While, the mean daily temperature varies from $5^{\circ} \mathrm{C}$ in winter to $30^{\circ} \mathrm{C}$ in summer; however, this might rise to $50^{\circ} \mathrm{C}$ in the southern parts of the region $[22,23]$.

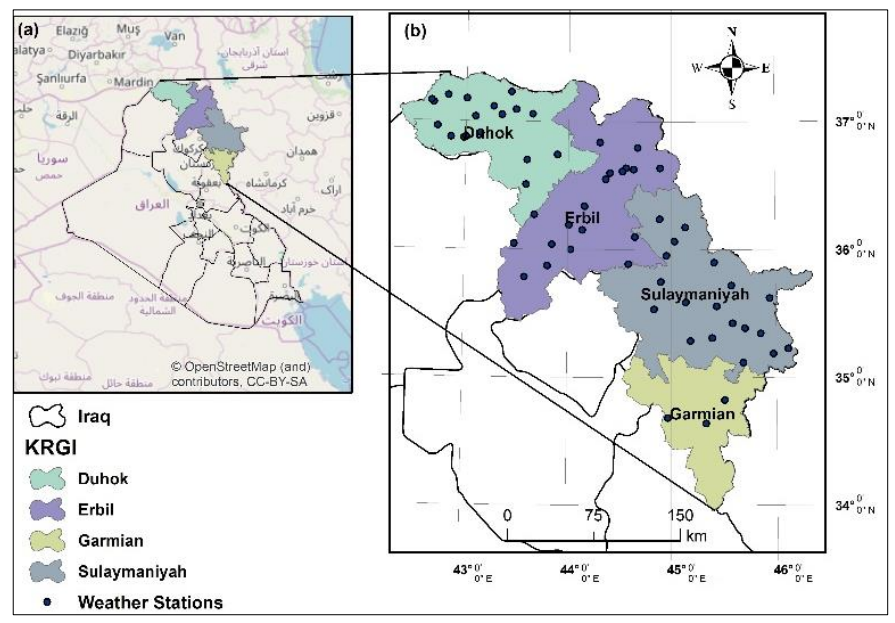

Fig. 1. Location of the study area, (a) Iraq Map, (b) KRGI map with weather stations location.

\section{DATA AND METHODS}

The methodology steps in this study is presented in Fig. 2.

\section{A. MODIS Data}

This study is based on the MODIS Terra land satellite data. MODIS has a 36-channel visible to thermal-infrared sensor with an FOV (field of view) of $\pm 55^{\circ}$, a scene width of $2230 \mathrm{~km}$, and a temporal resolution of 1-2 days. There are many standard MODIS data products that scientists are using to study global change. In this study MODIS NDVI 16-day level 3 product (MOD13Q1, collection 6) from Terra platform with 250-km spatial resolution was used. These data were downloaded from the MODIS website [24]. The NDVI product from MOD13Q1 MODIS is computed from atmospherically corrected bidirectional surface reflectance that have been masked for water, clouds, heavy aerosols, and cloud shadows. The geometrical corrections were performed, and the cloudy pixels were removed. The high quality pixels flagged were used for the analysis [25].

The form of NDVI [26] is shown in Eq. (1):

$$
N D V I=\frac{N I R-R e d}{N I R+R e d}
$$

Where NIR, Red, and Blue refer to the near-infrared, Red and blue reflectance bands, respectively.

In this study, 20 products (images) were collected from 2000 to 2019 , such that one image at June $10^{\text {th }}$ for each year were downloaded. They were used to determine variations of vegetation extent over whole KRGI annually, for a period of 20 years.

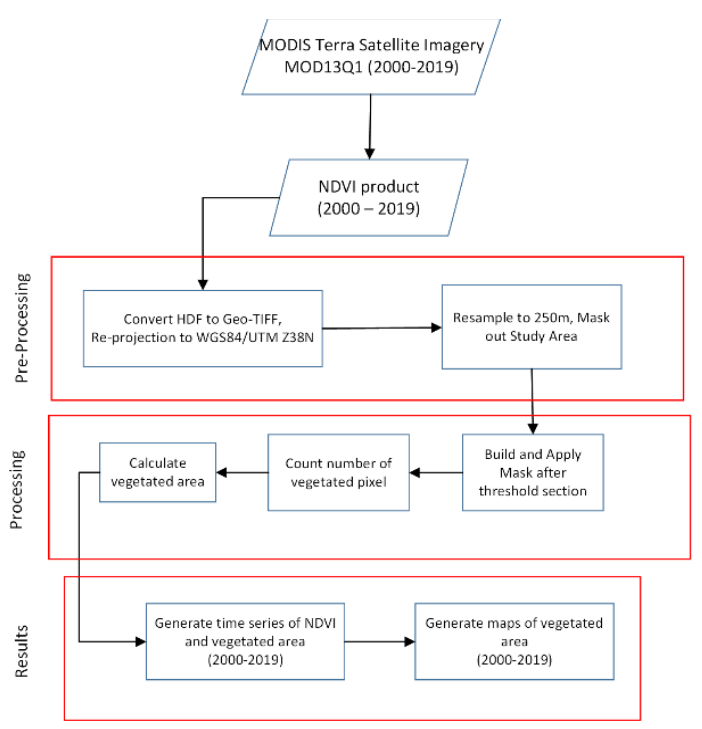

Fig. 2. Flow diagram showing the methodology steps.

\section{B. Climate Data}

Average temperature, and annual rainfall were collected over the 20 year period (2000-2019) from 60 weather stations, which are distributed over KRGI. The location of these stations are shown in Fig. 1(b). All climate data was provided by Ministry of Agriculture and Water Resources and Ministry of Planning at KRGI [22]. The most important climate data for vegetation is the precipitation. Therefore, the plot of precipitation along with the temperature are shown in Fig. 3.

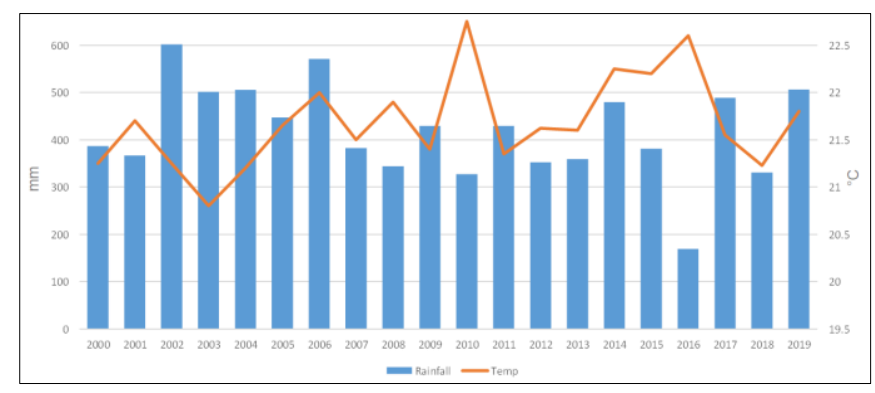

Fig. 3. Total annual rainfall and average temperature of 20 years for 60 stations in KRGI. 


\section{Methodology}

1) MOD13Q1 MODIS pre-processing: The time series MOD13Q1 MODIS data of 20 years $(2000$ - 2019) were acquaried from the Land Processes Distributed Active Archive Center (LP DAAC). The dataset were obtained in hdf format. They first converted to geo-tiff format and reprojected to WGS84/UTM Zone $38 \mathrm{~N}$. Moreover, the pixel size was resampled to $250 \mathrm{~m}$. Next, the study area (KRGI) were masked out. These steps were achieved for all 20 images.

2) MOD 13Q1 MODIS processing: In this stage, a vegetated area from non-vegetated area was identified. This is done through selecting a threshold experimentally for each NDVI image at each year. For the 20 years, the threshold values range was between 0.23 and 0.27 . Next the area of vegetation is calculated for each year and a time series graph was plotted. Further, the spatial variation was compared among these year and reported.

\section{RSULTES AND DISCSSION}

The mean, maximum, and minimum values of NDVI for the 20 years are shown in Fig. 4. It is reported that the NDVI values are low in 2000, 2008, and 2009. This is matching with the rainfall amount at the same year (Fig.3) as the amount of the rainfall in these year was lower than other years.

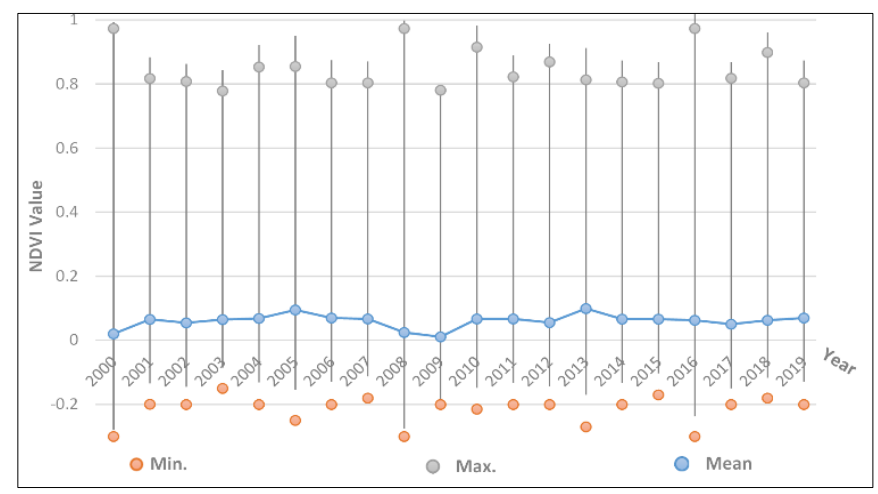

Fig. 4. NDVI time series from 2000 - 2019 in KRGI, comparing mean, minimum, maximum values.

Fig. 5 presents the vegetated area along with non-vegetated area over 20 years for the KRGI. The vegetated area is calculated from total number of vegetated pixels (Table 1). By comparing Fig. 5 with Fig. 3, a significant observation can be concluded as clear a relationship exist between precipitation and vegetated area. This is confirmed by Gaznayee and Al-Quraishi [27]. They found a strong relationship between vegetation and precipitation. However, the increase or decrease of vegetated area is not only effected by high/low amount of precipitation. The anthropogenic resource is also one of the main resources that has a major influence on the increase/decrease vegetation.

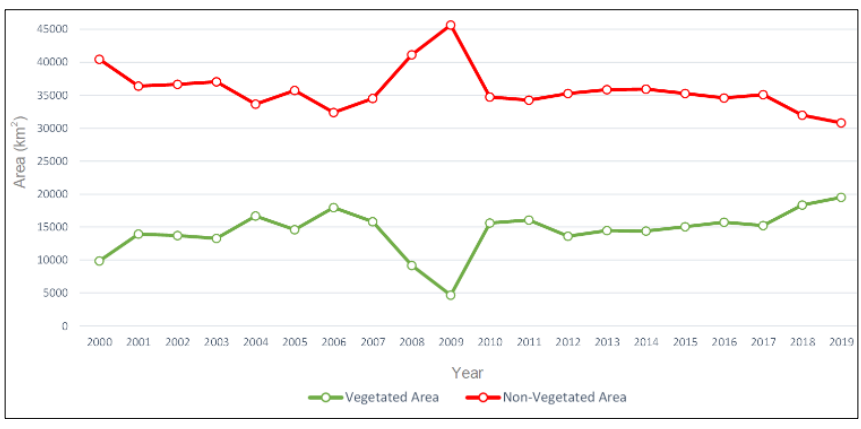

Fig. 5. The vegetated area with non-vegetated area of KRGI during 20 years.

TABLE I. VEgetated AREA For a PERIOd of 20 Years of KRGI

\begin{tabular}{|c|c|c|}
\hline \multirow{2}{*}{ Year } & \multicolumn{2}{|c|}{ Vegetated Area } \\
\cline { 2 - 3 } & No. of Pixel & Area $\mathbf{( k m}^{2}$ ) \\
\hline 2000 & 157860 & 9866.25 \\
\hline 2001 & 223153 & 13947.06 \\
\hline 2002 & 219456 & 13716.00 \\
\hline 2003 & 212609 & 13288.06 \\
\hline 2004 & 267047 & 16690.44 \\
\hline 2005 & 233729 & 14608.06 \\
\hline 2006 & 287364 & 17960.25 \\
\hline 2007 & 253012 & 15813.25 \\
\hline 2008 & 147152 & 9197.00 \\
\hline 2009 & 74824 & 4676.50 \\
\hline 2010 & 249751 & 15609.44 \\
\hline 2011 & 257182 & 16073.87 \\
\hline 2012 & 217917 & 13619.81 \\
\hline 2013 & 231588 & 14474.25 \\
\hline 2014 & 230314 & 14394.63 \\
\hline 2015 & 240972 & 15060.75 \\
\hline 2016 & 251965 & 15747.81 \\
\hline 2017 & 243846 & 15240.37 \\
\hline 2018 & 293509 & 18344.31 \\
\hline 2019 & 312450 & 19528.12 \\
\hline
\end{tabular}

The spatial variation of the NDVI-based vegetation results is displayed in Fig. 6. This results were confirmed and agreed with the statistical reports of the Ministry of Agriculture and Water resource in the KRGI, which indicated that low rainfall and high temperature in the KRI had happened in 2000, 2008, and 2009. It is also noticeable that the highest NDVI-based vegetation area was in the year 2018, and 2019. The NVDI-based vegetation that is higher than 0.6 value is observable in 2012 for both provinces Duhok and Erbil, and part of Sulimanyha province. However, in years of 2018 and 2019 with same NDVI-based vegetation value (>0.6) was only appear in Duhok province with small part of Erbil. The NDVI-based vegetation area with value between 0.2 and 0.6 was more marked in most of the study year except in the year of 2000, 2008, and 2009. Nonetheless, the larger are of NDVI-based vegetation within the range $0.2-0.6$ was measurable in the year of 2019. This results match with the amount of precipitation that is recorder in the study area between 2000 and 2019 (Fig.5). 


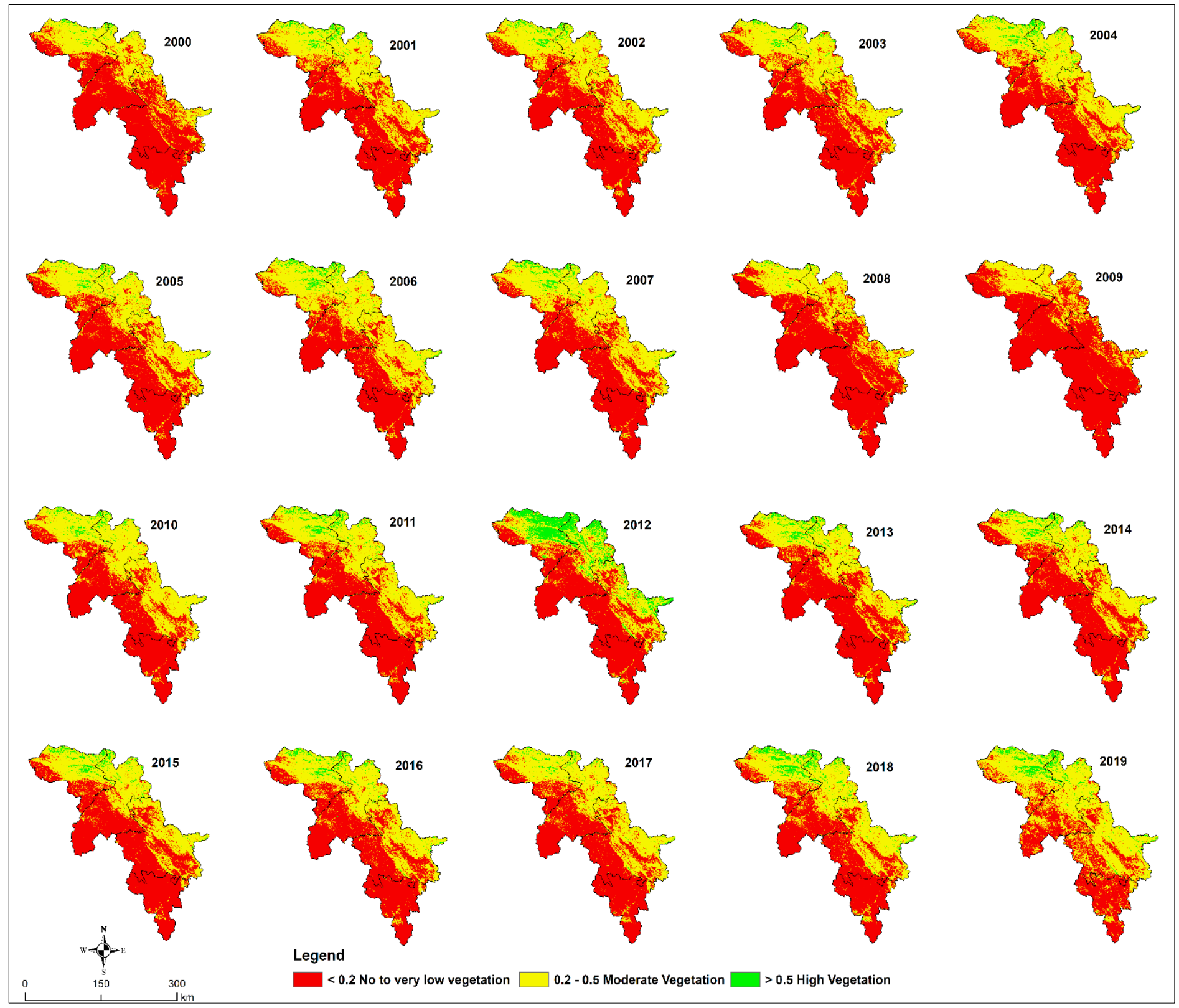

Fig. 6. Spatial variation of the NDVI-based vegetation from 2000 to 2019 in KGRI.

Fig. 7 illustrated the distributed vegetated cover area over KRGI for 20 years $(2000-2019)$. In general over 20 years, Duhok province comes in the first place as it has the largest vegetated cover area. Followed by Sulaymaniyah and Erbil, while the lower vegetated cover area is in Garmian. Here is also confirmed that the lower vegetated cover area in KRGI is observed in the years 2000, 2008, and 2009. The larger vegetated cover area in KRGI during this 20 years is in the years 2018, and 2019 (Table 2, Fig.7). Moreover, the moderate vegetated cover area is observed in the years 2001, 2003, 2005, 2010, 2014, and 2017. However, the lower vegetated cover area is in the years 2000, 2008, and 2009.
The spatial variation of vegetated cover area are distributed in the east part of KRGI from the north (large area) to the south (smaller area). This is due to the fact that these areas are mountainous areas which are suitable for vegetation and they are far from the human influences.

It is worth mentioning that this results is based on a coarse resolution $(250 \mathrm{~m})$ satellite data (MOD13Q1 MODIS). Therefore, calculated area might not be precise as the pixel cannot be break it down. For example, if more than half of the pixel is vegetation, then as an average the pixel will give one value indicating that the whole pixel is vegetation. Thus, to get rid of this limitation a satellite imagery with a finer resolution 
could be used. However, finer resolution images might not be available always at the same harmonic date as what is available in MODIS. From the other side, MODIS product is a composite data which facilitate the process of getting results.

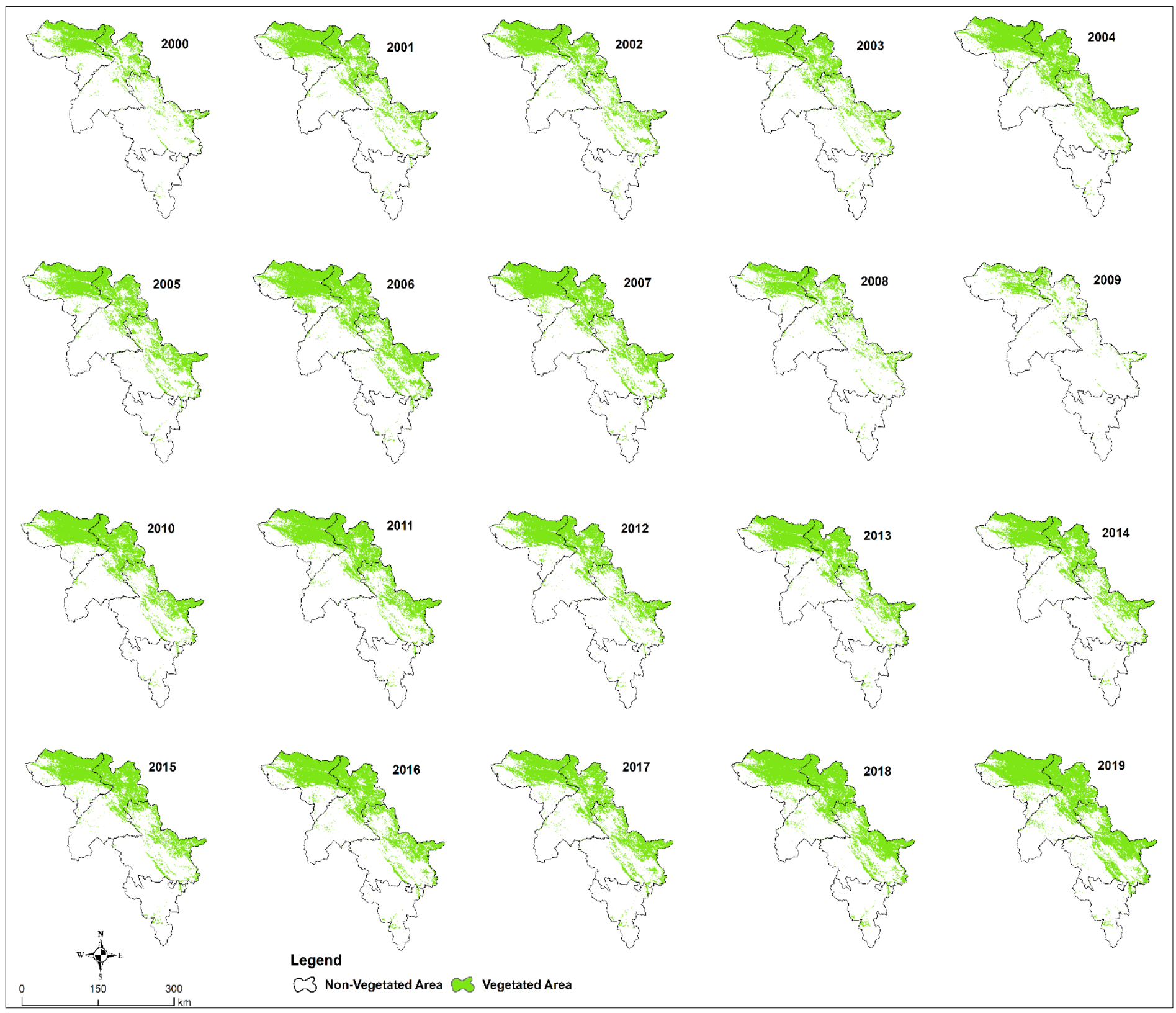

Fig. 7. Vegetated area of KRGI for the period of 20 year after NDVI threshold value selection of each year.

\section{CONCLUSION}

This study attempted to analyse the spatiotemporal variations of vegetation coverage in KRGI between 2000 and 2019 using MODIS data. This is performed by using time series NDVI-based vegetation that is obtained from MOD13Q1 MODIS product. The results of this study provide the following conclusions:
- The lower NDVI values in KRGI between 2000 and 2019 was in the years 2000, 2008, and 2009.

- The larger vegetated cover area in KRGI during 20 years was in the years 2018, and 2019. However, the smaller vegetated cover area was in the years 2000, 2008, and 2009.

- The spatial distribution of NDVI-based vegetation in KRGI was generally focused in the northeast to southeast. 
- During the period of 20 years $(2000-2019)$, the most dominated vegetation province was Duhok province in KRGI.

- Considering vegetation distribution in KRGI and according to collected MODIS data, the KRGI manifested high levels of vegetation regardless of the period of the year.

\section{REFERENCES}

[10] S. L. Furby, P. A. Caccetta, J. F. Wallace, E. A. Lehmann, and $\mathrm{K}$. Zdunic, "Recent development in vegetation monitoring products from Australia's National Carbon Accounting System," in Geoscience and Remote Sensing Symposium, 2009 IEEE International, IGARSS 2009, 2009, pp. IV-276-IV-279.

[11] R. B. Myneni, R. Ramakrishna, R. Nemani, and S. W. Running, "Estimation of global leaf area index and absorbed par using radiative transfer models," Geoscience and Remote Sensing, IEEE Transactions on, vol. 35, pp. 1380-1393, 1997.
[12] Y. T. Mustafa, T. K. Salih, And M. H. Obeyed, "Estimating of Diameter at Breast Height for Scattered Pinusbrutiaten. Trees using Remote Sensing Techniques, in Zawita Sub-District, Duhok, Kurdistan Region-Iraq," in The 2nd Scientific Agricultural Conference, p. 311.

[13] Y. T. Mustafa and H. N. Habeeb, "Landsat LDCM Imagery for Estimating and Mapping Burned Forest Areas Caused By Jet Attacks in Duhok Governorate, Kurdistan Region - Iraq," Journal of University of Duhok, vol. 19, pp. 683-690, 2016.

[14] T. Pisman, A. Shevyrnogov, A. Larko, I. Botvich, D. Emelyanov, A. Shpedt, et al., "The Information Content of Spectral Vegetation Indices in the Interpretation of Satellite Images of Cultivated Fields," Biophysics, vol. 64, pp. 588-592, 2019.

[15] J. Svejkovsky, D. E. Ogurcak, M. S. Ross, and A. Arkowitz, "Satellite Image-Based Time Series Observations of Vegetation Response to Hurricane Irma in the Lower Florida Keys," Estuaries and Coasts, pp. 1-12, 2020.

[16] H. Karimi, J. Jafarnezhad, J. Khaledi, and P. Ahmadi, "Monitoring and prediction of land use/land cover changes using CA-Markov model: a case study of Ravansar County in Iran," Arabian Journal of Geosciences, vol. 11, p. 592, 2018/10/06 2018.

[17] H. Karimi, "Application of Remote Sensing in Diseases Monitoring and Dispersion," Int J Health Life Sci, vol. 6, p. e100288, 2020.

[18] Y. T. Mustafa, "Satellite Remote Sensing for Spatio-Temporal Estimation of Leaf Area Index in Heterogeneous Forests," International Journal of Environmental Protection, vol. 3, pp. 10-16, 2013.

[19] M. Gholamnia, R. Khandan, S. Bonafoni, and A. Sadeghi, "Spatiotemporal Analysis of MODIS NDVI in the Semi-Arid Region of Kurdistan (Iran)," Remote Sensing, vol. 11, p. 1723, 2019.

[20] J. Deka, S. Kalita, and M. L. Khan, "Vegetation Phenological Characterization of Alluvial Plain Shorea robusta-dominated Tropical Moist Deciduous Forest of Northeast India Using MODIS NDVI Time Series Data," Journal of the Indian Society of Remote Sensing, vol. 47, pp. 1287-1293, 2019/08/01 2019.

[21] S. O. Hussein, F. Kovács, and Z. Tobak, "Spatiotemporal assessment of vegetation indices and land cover for Erbil city and its surrounding using MODIS imageries," Journal of Environmental Geography, vol. 10, pp. 31-39, 2017.

[22] M. O. PLANNING-KRG, "Regional Development Strategy for Kurdistan Region," 2017.

[23] L. Eklund, A. Abdi, and M. Islar, "From producers to consumers: the challenges and opportunities of agricultural development in Iraqi Kurdistan," Land, vol. 6, p. 44, 2017.

K. Didan, "MOD13Q1 MODIS/Terra Vegetation Indices 16Day L3 Global 250m SIN Grid V006. NASA EOSDIS LP DAAC," Retrieved from https://lpdaac.usgs.gov/products/mod13q1v006/, vol. 10, 2015.

[25] K. Didan, A. B. Munoz, R. Solano, and A. Huete, "MODIS vegetation index user's guide (MOD13 series)," University of Arizona: Vegetation Index and Phenology Lab, 2015.

[26] A. Huete, K. Didan, T. Miura, E. P. Rodriguez, X. Gao, and L. G. Ferreira, "Overview of the radiometric and biophysical performance of the MODIS vegetation indices," Remote sensing of environment, vol. 83, pp. 195-213, 2002. 
Yaseen T. Mustafa / Journal of Applied Science and Technology Trends Vol. 01, No. 01, pp. 01 -07, (2020)

[27] H. A. A. Gaznayee and A. M. F. Al-Quraishi, "Analysis of Agricultural Drought, Rainfall, and Crop Yield Relationships in Erbil Province, the Kurdistan Region of Iraq based on Landsat

Time-Series MSAVI2," Journal of Advanced Research in Dynamical and Control Systems, vol. 11, pp. 536-545. 